\title{
Three Steps towards Metrological Traceability for Ballistics Signature Measurements
}

\author{
J. Song, T. Vorburger, R. Thompson, T. Renegar, A. Zheng, L. Ma, J. Yen, M. Ols ${ }^{1}$ \\ National Institute of Standards and Technology (NIST), Gaithersburg, MD 20899, U.S.A. song@nist.gov, \\ ${ }^{1}$ Bureau of Alcohol, Tobacco, Firearms and Explosives (ATF), Ammendale, MD 20705, U.S.A. martin.als@atf.gov
}

\begin{abstract}
The National Institute of Standards and Technology (NIST) in collaboration with the Bureau of Alcohol, Tobacco, Firearms and Explosives (ATF) has developed the Standard Reference Material (SRM) bullets and casings. NIST and ATF are proposing to establish a National Ballistics Measurement Traceability and Quality System for ballistics signature measurements and correlations using these materials. In this paper, three key steps towards metrological traceability for ballistics signature measurements are discussed that include: 1) Establishing a reference standard; 2) Establishing an unbroken chain of calibrations; and 3) Evaluating measurement uncertainty.
\end{abstract}

Keywords: Traceability, forensic science, ballistics signature, standard reference material, standard bullet, standard casing

\section{INTRODUCTION}

$\mathrm{T}$ HE National Institute of Standards and Technology (NIST) in collaboration with the Bureau of Alcohol, Tobacco, Firearms and Explosives (ATF) has developed the Standard Reference Material (SRM) bullets and casings [1, 2]. NIST and ATF are proposing to establish a National Ballistics Measurement Traceability and Quality System for ballistics signature measurements and correlations using these materials [3]. In this paper, three key steps towards metrological traceability for ballistics signature measurements are discussed that include: 1) Establishing a reference standard; 2) Establishing an unbroken chain of calibrations; and 3) Evaluating measurement uncertainty.

\section{Three Steps towards Metrological Traceability FOR BALLISTICS SigNATURE MEASUREMENTS}

According to the International vocabulary of metrology Basic and general concepts and associated terms (VIM) [4], metrological traceability is defined as:

property of a measurement result whereby the result can be related to a reference through a documented unbroken chain of calibrations, each contributing to the measurement uncertainty

From the above definition, three key steps for establishing metrological traceability for ballistics measurements are:

- Establish a reference standard for ballistics signature measurements;

- Establish an unbroken chain of calibrations from the national laboratory (NIST and the National Laboratory Center of ATF) to local laboratories and users using the reference standard; and

- Evaluate measurement uncertainty.

\section{ESTABLISH A REFERENCE STANDARD - NIST SRM 2460/2461 STANDARD BULLETS AND CASINGS}

A SRM 2460 standard bullet is shown in Fig.1, left, which is designed as both a virtual and a physical ballistics signature standard [1]. The virtual standard is a set of digitized bullet profile signatures that provides the profiles for machining the bullet signatures on the physical standards, the SRM bullets. The virtual standard also provides reference profiles for the measurements of the machined bullet signatures on the SRM bullets. The virtual standard was originally obtained from topographic profiles traced by a stylus instrument on master bullets fired at the ATF and the Federal Bureau of Investigation (FBI) under standardized shooting procedures [1]. The virtual standard was stored in a computer and used for control of the tool path of a numerically controlled (NC) diamond turning machine at the NIST Instrument Shop to machine the bullet signatures on the SRM bullets [1].

Two SRM 2461 standard casing prototypes are shown in Fig.1, right. These are replicated from an ATF master casing using the electro-forming technique [1]. We intend to fabricate 256 replica casings with essentially the same topography. However, each replication can potentially degrade the master surface. In order to ensure that enough SRM casings are produced with virtually the same surface topography as the master, we tested the "decay factors" for the replication process [5], that is, how fast the replication process itself will degrade the surface topography of the master. Test results have shown that the decay factors are very small and indicate that the topography of 256 SRM casings replicated from the same ATF master can be highly reproducible [5]. Production of the SRM casings is currently in progress. Up to date, 173 SRM casings have been delivered and are undergoing testing. We anticipate delivery a total of 256 SRM casings in 2010. 


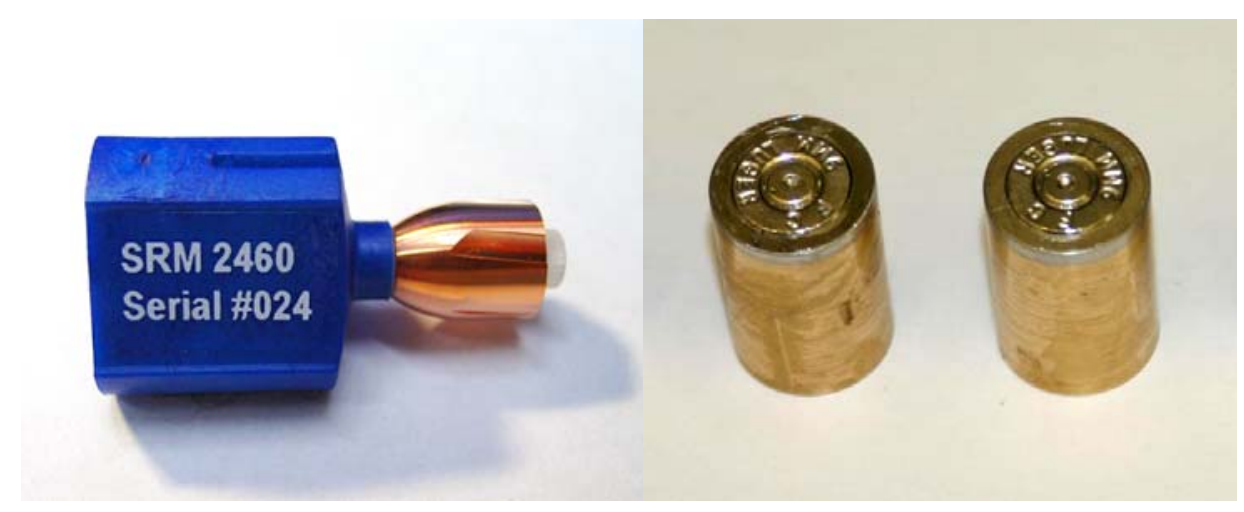

Fig.1 A SRM 2460 standard bullet (left) and two prototype SRM 2461 standard casings produced for testing the reproducibility of the electroforming process.

\section{ESTABLISH AN UNBROKEN CHAIN OF CALIBRATIONS}

Considering that topography measurements are used to demonstrate the reproducibility of the SRM standards and that reflection microscopy is used for image comparisons in case work, the unbroken calibration chain must include both geometric topography measurements and optical image comparisons.

The NIST 2D and 3D Topography Measurement and Correlation System is essential for the "unbroken chain of calibration" of the topography signatures of the SRM bullets and casings. Two property values, a NIST proposed parameter called the topography difference $D_{s}$ and the cross correlation function maximum $C C F_{\max }$, are calculated for both $2 \mathrm{D}$ and $3 \mathrm{D}$ ballistics signature measurements [1, 2]. $C C F_{\max }$ is the maximum value of the cross correlation function (CCF), which occurs when the two correlated surface topographies, the measured topography $Z_{(B)}$ and the reference topography $\mathrm{Z}_{(\mathrm{A})}$, are registered at their maximum correlation position. At this position, a new topography $Z_{(B-A)}$ is calculated which equals the difference between topography $Z_{(B)}$ and $Z_{(A)}$. The second parameter, the topography difference $D_{s}$, is defined as a ratio of the mean-square roughness $R q^{2}$ of the topography difference $\left.Z_{(B}-A\right)$ and the mean-square roughness of the reference topography $\mathrm{Z}_{(\mathrm{A})}$ :

$$
D_{s}=R q_{(\mathrm{B}-\mathrm{A})}^{2} / R q_{(\mathrm{A})}^{2}
$$

When the compared topography $\mathrm{Z}_{(\mathrm{B})}$ is exactly the same as the reference topography $\mathrm{Z}_{(\mathrm{A})}$ (point by point), $D_{s}$ is equal to 0 (and $C C F_{\max }$ must be $100 \%$ ). Both parameters are calculated because the value of $C C F_{\max }$ is not sensitive to a difference in scale height between two topographies with similar shape, whereas the value of $D_{s}$ is sensitive to a scale difference.

After the topography measurements at NIST, the SRM bullets were sent to the National Laboratory Center of ATF and measured using their Integrated Ballistics Identification System* (IBIS $^{\mathrm{TM}}$ ) [6]. From these measurements, a set of the best images has been selected as reference image standards, or Golden Images, against which the images of SRM bullets acquired at local forensic laboratories may be correlated for establishing measurement traceability and quality assurance [3]. Fig.2 shows the Golden Images for six land engraved areas (LEAs) of the SRM 2460 standard bullets. The LEAs represent contact areas with the barrel during firing.

\section{EVALUATE MEASUREMENT UNCERTAINTY}

For the topography measurements of the SRM bullets using the NIST Topography Measurement and Correlation System, a statistical procedure has been established for evaluating and reporting the uncertainty of correlations and differences between topographies of the SRM bullets. For the measurement uncertainty of the ballistics image correlations, the IBIS scores [6] provide a quantitative estimation of the similarity of a pair of compared ballistics images. However, both the definition and the algorithm for IBIS scores are proprietary. In order to report the uncertainty of IBIS correlations, a NIST and ATF joint project is currently in progress, in which the SRM bullet and casing are routinely tested at participating laboratories; the tested images are correlated with the Golden Images established at the National Laboratory Center of ATF. This project calls for about 24 ballistics signature acquisitions of both an SRM bullet and SRM casing in 13 participating laboratories in the United States. The acquisition phase will take about a year to complete. The correlation scores are to be entered on a spreadsheet developed by NIST for statistical analyses, and measurement uncertainty will be evaluated. The correlated IBIS scores are statistically analyzed for determining the systematic and random variations arising from the influence quantities, including the reference standards (SRM bullets and casings), the IBIS systems, the operators and the operating conditions, and the environment variations in different IBIS sites, from which an uncertainty procedure is being developed for reporting the uncertainty of IBIS measurements.

Certain commercial equipment, instruments, or materials are identified in this paper to specify adequately the experimental procedure. Such identification does not imply recommendation or endorsement by the National Institute of Standards and Technology, nor does it imply that the materials or equipment identified are necessarily the best available for the purpose. 


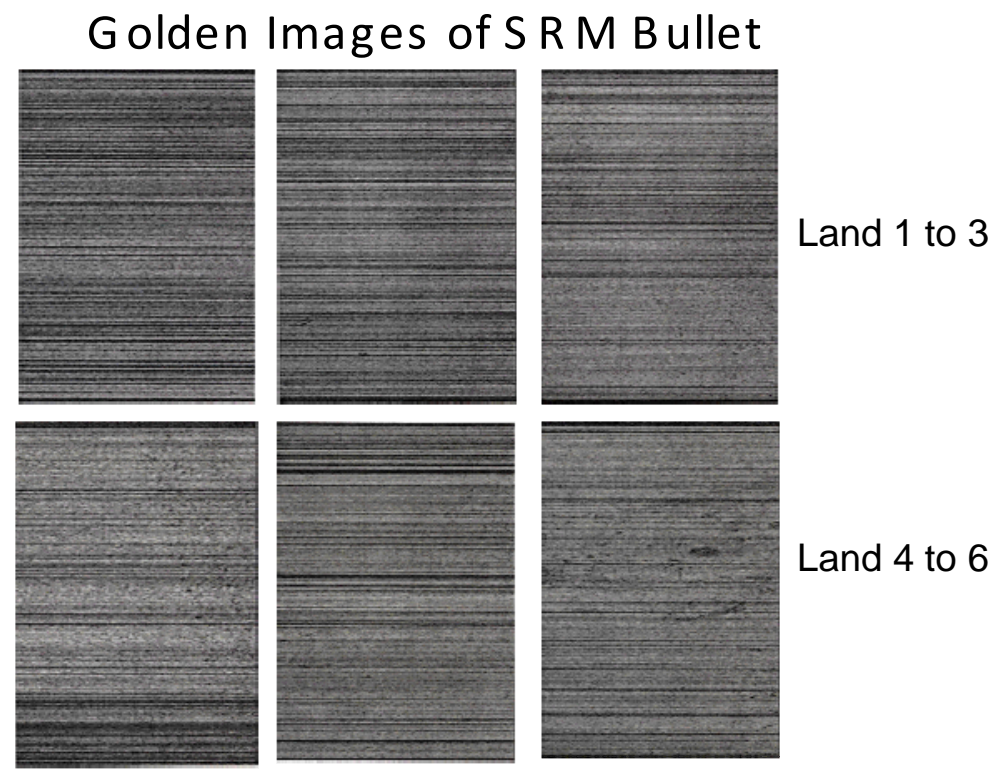

Fig.2 The "Golden Image” for six land engraved areas (LEA) of the SRM 2460 bullets

\section{SUMMARY}

Three steps towards metrological traceability for ballistics signature measurements are discussed in this paper, that include: 1) Establishing a reference standard; 2) Establishing an unbroken chain of calibrations; and 3) Evaluating measurement uncertainty.

The NIST SRM 2460 standard bullets have been developed and used as the reference standards. The NIST 2D and 3D Topography Measurement System with a new parameter proposed by us has been established and used for the measurement and correlation of 2D and 3D ballistics signatures, and is traceable to the SI unit of length. An uncertainty procedure is developed for reporting the measurement uncertainty of SRM bullets.

The SRM 2461 standard casings are currently under developing and scheduled for delivery in 2010.

\section{ACKNOWLEDGEMENT}

The funding for this research was provided by the National Institute of Justice (NIJ) through the Office of Law Enforcement Standards (OLES) at NIST. The authors are grateful to S. Ballou, E. Whitenton and D. Kelley of NIST and to P. Rubert of Rubert Co. Ltd. in UK for their contributions in the development the NIST SRM 2460 bullets and 2461 casings.

\section{REFERENCES}

[1] Song, J., Whitenton, E., Kelley, D., Clary, R., Ma, L. \& Ballou, S. (2004). SRM 2460/2461 standard bullets and casings project, J. Res. Natl. Inst. Stand. Technol. 109(6), 533-542.

[2] Ma, L., Song, J., Whitenton, E., Zheng, A. \& Vorburger, T. (2004). NIST bullet signature measurement system for SRM (standard reference material) 2460 standard bullets, Journal of Forensic Sciences, 49(4), 64-659.

[3] Song, J., Vorburger, T., Renegar, T., Zheng, A., Hilton, A, Silver, R., Ballou, S. \& Ols, M. (2008). Establishing the golden images of NIST SRM standard bullets and casings for nationwide ballistics measurement traceability and quality system, the $39^{\text {th }}$ Annual Training Seminar of Association of Firearm and Tool-mark Examiners (AFTE), Honolulu, HV, 2008.

[4] BIPM, IEC, IFCC, ILAC, ISO, IUPAC, IUPAP \& OIML, International vocabulary of metrology - Basic and general concepts and associated terms (VIM), JCGM 200:2008.

[5] Song, J., Rubert, P., Zheng, A. \& Vorburger, T. (2008). Topography measurements for determining the decay factors in surface replication, Measurement Science and Technology, 19(8), 1-4, 2008.

[6] Forensic Technology, Inc. (FTI): http: //www.ftiibis.com/en/s415. asp, Bulletrax - 3D, Accessed, 06 Dec 2005. 